University of Nebraska - Lincoln

DigitalCommons@University of Nebraska - Lincoln

Faculty Publications from the Department of Electrical \& Computer Engineering, Department Electrical and Computer Engineering

2011

\title{
Formation of graphene sheets through laser exfoliation of highly ordered pyrolytic graphite
}

\author{
Min Qian \\ University of Nebraska-Lincoln \\ Yun-Shen Zhou \\ University of Nebraska-Lincoln, yzhou5@unl.edu \\ Yang Gao \\ University of Nebraska-Lincoln \\ Jong Bok Park \\ University of Nebraska-Lincoln \\ Tao Feng \\ East China Normal University
}

See next page for additional authors

Follow this and additional works at: https://digitalcommons.unl.edu/electricalengineeringfacpub

Part of the Computer Engineering Commons, and the Electrical and Computer Engineering Commons

Qian, Min; Zhou, Yun-Shen; Gao, Yang; Park, Jong Bok; Feng, Tao; Huang, Su Mei; Sun, Zhuo; Jiang, Lan; and Lu, Yongfeng, "Formation of graphene sheets through laser exfoliation of highly ordered pyrolytic graphite" (2011). Faculty Publications from the Department of Electrical and Computer Engineering. 223. https://digitalcommons.unl.edu/electricalengineeringfacpub/223

This Article is brought to you for free and open access by the Electrical \& Computer Engineering, Department of at DigitalCommons@University of Nebraska - Lincoln. It has been accepted for inclusion in Faculty Publications from the Department of Electrical and Computer Engineering by an authorized administrator of DigitalCommons@University of Nebraska - Lincoln. 
Authors

Min Qian, Yun-Shen Zhou, Yang Gao, Jong Bok Park, Tao Feng, Su Mei Huang, Zhuo Sun, Lan Jiang, and Yongfeng Lu 


\title{
Formation of graphene sheets through laser exfoliation of highly ordered pyrolytic graphite
}

\author{
Min Qian, ${ }^{1,2}$ Yun Shen Zhou, ${ }^{1}$ Yang Gao, ${ }^{1}$ Jong Bok Park, ${ }^{1}$ Tao Feng, ${ }^{2}$ Su Mei Huang, ${ }^{2}$ \\ Zhuo Sun, ${ }^{2}$ Lan Jiang, ${ }^{3}$ and Yong Feng $\mathrm{Lu}^{1, a)}$ \\ ${ }_{1}^{1}$ Department of Electrical Engineering, University of Nebraska-Lincoln, Lincoln, Nebraska 68588, USA \\ ${ }^{2}$ Department of Physics, East China Normal University, Shanghai 200062, People's Republic of China \\ ${ }^{3}$ Department of Mechanical and Automation Engineering, Beijing Institute of Technology, Beijing 100081, \\ People's Republic of China
}

(Received 21 February 2011; accepted 6 April 2011; published online 28 April 2011)

\begin{abstract}
Freestanding two-dimensional (2D) few-layer graphene was formed through laser exfoliation of highly ordered pyrolytic graphite, using a pulsed neodymium-doped yttrium aluminum garnet (Nd:YAG) laser. Graphene sheets of several nanometers in thickness and micrometers in size were obtained. The laser exfoliation process was investigated at different laser fluences and distances between target and substrate. Three different phases, amorphous carbon, few-layer graphene sheets, and thin graphite films, were obtained as the laser fluence increased. This study reveals an existing route of forming freestanding 2D nanostructures through laser exfoliation. (c) 2011 American Institute of Physics. [doi:10.1063/1.3584021]
\end{abstract}

Since the discovery of two-dimensional (2D) graphene in $2004,{ }^{1}$ investigations on the single-layer $s p^{2}$ carbon network have increased exponentially, due to its extraordinary carrier mobility $^{2}$ and potential applications in electronics. ${ }^{3}$ Several methods have been investigated to synthesize graphene, such as mechanical exfoliation, ${ }^{1}$ epitaxial growth on silicon carbide $^{4}$ or metal substrates, ${ }^{5}$ and chemical exfoliation. ${ }^{6}$ Among these methods, mechanical exfoliation offers the pristine graphene by a repetitive stick and peel process from highly ordered pyrolytic graphite (HOPG), ${ }^{7}$ which avoids the high temperature, long processing time, and metal catalyst in epitaxial growth, ${ }^{4,5}$ as well as the permanent $s p^{2}$ structural damage in chemical exfoliation. ${ }^{6}$ Nevertheless, mechanical exfoliation is labor intensive, and it leaves glue residues on samples which require high temperature post-treatments. ${ }^{8}$ To address this issue, simple and fast laser exfoliation of HOPG was developed to obtain graphene.

Pulsed lasers have been employed for growth of carbon nanostructures of different dimensions, including fullerenes, ${ }^{9}$ carbon nanotubes, ${ }^{10}$ graphite and diamond-like carbon. ${ }^{11}$ In this study, the formation of freestanding $2 \mathrm{D}$ graphene was achieved through laser exfoliation of HOPG using a pulsed neodymium-doped yttrium aluminum garnet (Nd:YAG) laser. The laser exfoliation process was investigated as a function of laser fluence and distance between target and substrate. Carbon nanostructures of different phases were obtained, including amorphous carbon, graphene, and thin graphite films.

The experimental setup is shown in Fig. 1(a). After loaded with a commercial HOPG sample (SPI Supplies, $446 \mathrm{HP}-\mathrm{AB})$ as the target and a bare silicon ( $\mathrm{Si})$ wafer as the substrate, the chamber was vacuumed to $10^{-5}$ Torr and then filled with argon gas to 1 Torr. A pulsed Nd:YAG laser (Continuum Powerlite ${ }^{\mathrm{TM}}$ Precision II DLS 8010, wavelength $=532 \mathrm{~nm}, \tau=7 \mathrm{~ns}$ ) with a repetition rate of $1 \mathrm{~Hz}$ was used

\footnotetext{
a) Author to whom correspondence should be addressed. Tel.: (402) 472 8323. FAX: (402) 472-4732. Electronic mail: ylu2@unl.edu.
}

as the irradiation source with laser fluences from 0.8 to $20.0 \mathrm{~J} / \mathrm{cm}^{2}$. The laser beam was focused to $1 \mathrm{~mm}$ and irradiated the HOPG surface at an incident angle of $45^{\circ}$ at room temperature. The same spot of the HOPG was irradiated for only 1 or 2 pulses. Si substrates were used to collect the ablated carbon materials. In a laser fluence range from 1.0 to $10.0 \mathrm{~J} / \mathrm{cm}^{2}$, ultrathin sheet fragments were peeled off from the HOPG, and deposited on the substrate as graphene, as shown in Fig. 1(b). A scanning electron microscope (SEM, Hitachi S-4700), a high-resolution transmission electron microscope (TEM, FEI Tecnai T12), an atomic force microscope (AFM, Veeco DI-3100), and a micro-Raman spectrometer (Renishaw inVia, excitation wavelength of $514 \mathrm{~nm}$ ) were used to study the graphene sheets.

Figure 2 shows the Raman spectra of HOPG and graphene obtained at a laser fluence of $5.0 \mathrm{~J} / \mathrm{cm}^{2}$. G band around $1580 \mathrm{~cm}^{-1}$ and $2 \mathrm{D}$ band near $2700 \mathrm{~cm}^{-1}$ are the most prominent Raman features of graphene. ${ }^{12}$ The $\mathrm{G}$ bands

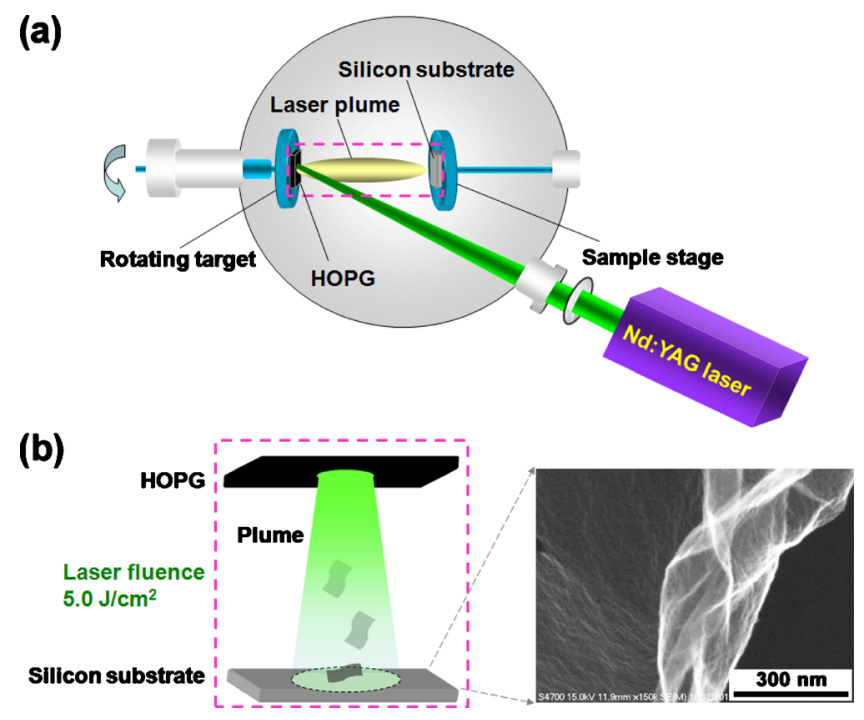

FIG. 1. (Color online) (a) Schematic of the experimental setup. (b) Illustration of the formation of few-layer graphene through laser exfoliation of HOPG 


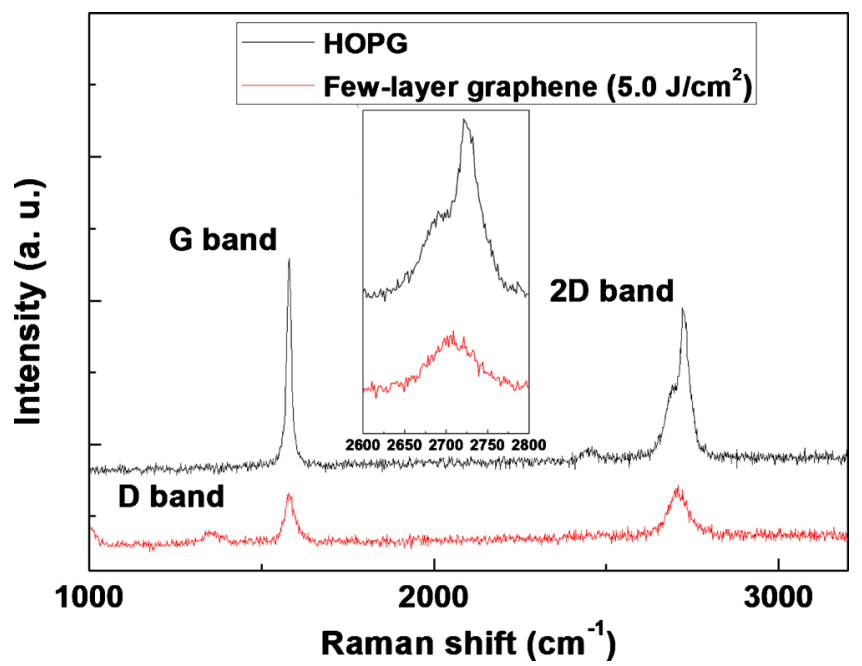

FIG. 2. (Color online) Raman spectra of HOPG and few-layer graphene.

from both HOPG and graphene appear at $1580 \mathrm{~cm}^{-1}$ (Fig. 2 ). The $2 \mathrm{D}$ band of graphene is at $2700 \mathrm{~cm}^{-1}$, with symmetrical shape and full width at half maximum (FWHM) of $\sim 65 \mathrm{~cm}^{-1} \cdot{ }^{13} \mathrm{HOPG}$ has a broader and upshifted 2D band at $2720 \mathrm{~cm}^{-1}$, compared with the few-layer graphene. ${ }^{12,13}$ The $\mathrm{I}_{\mathrm{G}} / \mathrm{I}_{2 \mathrm{D}}$ ratios of the HOPG and the few-layer graphene are 1.37 and 0.87 , respectively. ${ }^{12}$ The weak $\mathrm{D}$ band near $1350 \mathrm{~cm}^{-1}$ refers to the disorder in $s p^{2}$ carbon network. ${ }^{14}$ Figure 3(a) shows an AFM image indicating a $3.9 \mathrm{~nm}$ thick graphene. Figure 3(b) is a low-magnification TEM image showing a transparent graphene with several micrometers in size as well as rippled and folded morphologies. As shown in Fig. 3(c), the high-magnification TEM image located at the folded edges shows a ten-layer graphene. ${ }^{12}$

To study the mechanism of graphene formation, the laser exfoliation process was studied as a function of laser fluence. The deposited carbon materials can be classified into three categories: amorphous carbon, few-layer graphene, and thin

(a)

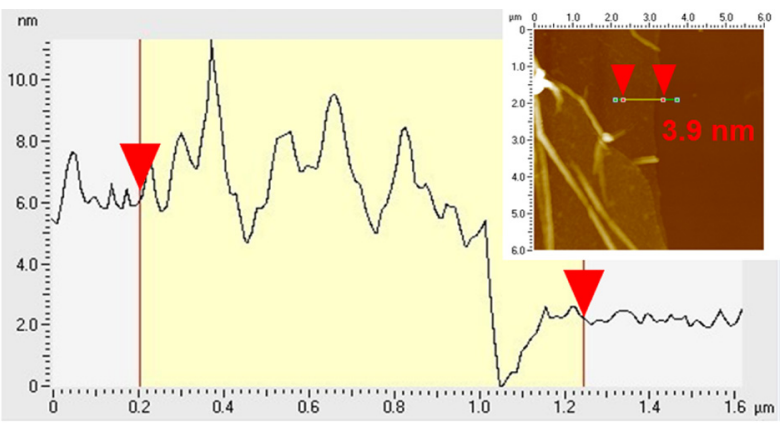

(b)

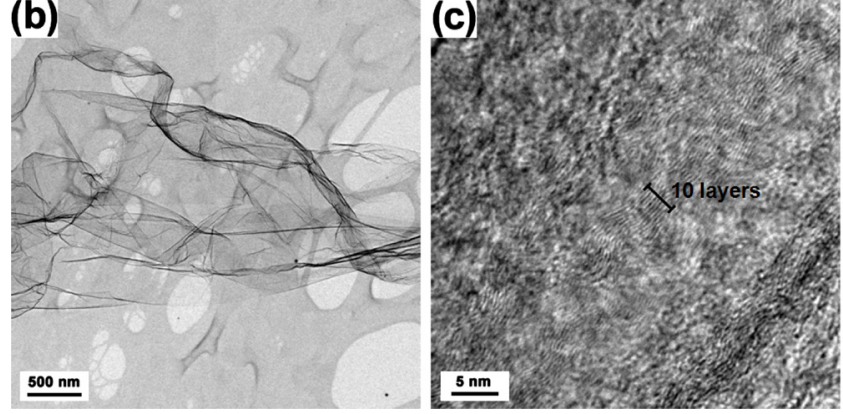

FIG. 3. (Color online) (a) AFM measurements show a $3.9 \mathrm{~nm}$ thick graphene. (b) Low-magnification and (c) high-magnification TEM images of a ten-layer graphene. graphite films, as shown in Fig. 4. Nothing was obtained on the substrate below $0.8 \mathrm{~J} / \mathrm{cm}^{2}$, which was estimated to be the ablation threshold ${ }^{15}$ of HOPG. Amorphous carbon was deposited at $0.8 \mathrm{~J} / \mathrm{cm}^{2}$, with SEM image and Raman spectrum shown in Figs. 4(a) and 4(b). ${ }^{16}$ The graphene was obtained from 1.0 to $10.0 \mathrm{~J} / \mathrm{cm}^{2}$. As shown in Fig. 4(c), the graphene obtained at $5.0 \mathrm{~J} / \mathrm{cm}^{2}$ shows an ultrathin morphology. Corresponding Raman spectrum is shown in Fig. 4(d). At a higher laser fluence, such as $20.0 \mathrm{~J} / \mathrm{cm}^{2}$, thin graphite films appeared, as shown in Fig. 4(e). The increase in $\mathrm{I}_{\mathrm{G}} / \mathrm{I}_{2 \mathrm{D}}$ ratio and the FWHM of 2D band of thin graphite films in Fig. 4(f) indicates the increase in film thickness, ${ }^{12-14}$ as compared with those of few-layer graphene in Fig. 4(d). Based on the experimental observations, the formation mechanism of 2D few-layer graphene in laser exfoliation is suggested as follows.

Photothermal and photochemical processes are frequently considered in laser ablation. ${ }^{16,17}$ The $\mathrm{C}-\mathrm{C}$ bond energy of the ground electronic states in HOPG is estimated to be $3.7 \mathrm{eV} .^{18}$ The photon energy equivalent to a wavelength of $532 \mathrm{~nm}$ is $2.3 \mathrm{eV}$, not sufficient for direct photochemical bond breaking. Therefore, the photothermal mechanism plays a major role in the laser exfoliation.

Ablation depth of the HOPG target is another factor to be considered. ${ }^{19}$ The HOPG is ablated into single atoms, molecules, clusters, or fragments, at different laser fluences. ${ }^{20}$ A laser fluence of $0.8 \mathrm{~J} / \mathrm{cm}^{2}$ is not sufficient to ablate the HOPG into nanosheets as the target surface does not change after the laser irradiation. From 1.0 to $10.0 \mathrm{~J} / \mathrm{cm}^{2}$, the laser energy is sufficient to ablate the HOPG into graphene sheets a few nanometers thick. A laser pulse of higher fluence $\left(20.0 \mathrm{~J} / \mathrm{cm}^{2}\right)$ ablates the HOPG into thin graphite films, with a thickness between 50 and $200 \mathrm{~nm}$.

Consequently, the HOPG is thermally decomposed into monomers and small clusters below $1.0 \mathrm{~J} / \mathrm{cm}^{2}$, which are deposited as amorphous carbon. ${ }^{21}$ Between 1.0 and $10.0 \mathrm{~J} / \mathrm{cm}^{2}$, the main product of few-layer graphene confirms that more macromolecules or large sheet fragments, rather than small molecules or clusters, are ablated from the HOPG target. ${ }^{22}$ The influence of distance between target and substrate was studied from 15 to $60 \mathrm{~mm}$. The distance does not affect the formation of the three carbon phases within their fluence range.

HOPG has a layered structure and is made of many graphene layers, which is essential for the graphene formation by laser exfoliation. ${ }^{7}$ HOPG and compressed graphite tablets were used for comparison. Under the same condition from 0.8 to $20.0 \mathrm{~J} / \mathrm{cm}^{2}$, amorphous carbon was the only product from the compressed graphite tablets while graphene was obtained from the HOPG target.

In summary, we discovered an existing route for the formation of 2D few-layer graphene using pulsed laser exfoliation of HOPG. Graphene sheets of a few nanometers in thickness and tens of micrometers in size were obtained. With the increase in laser fluence (from 0.8 to $20.0 \mathrm{~J} / \mathrm{cm}^{2}$ ), three different carbon phases, amorphous carbon, few-layer graphene, and thin graphite films, were formed. The formation mechanism was suggested: a pristine $s p^{2}$ carbon target with a plane surface (HOPG), a laser with photon energy lower than $\mathrm{C}-\mathrm{C}$ bond energy $(3.7 \mathrm{eV})$, and an appropriate ablation depth contributed to the formation of few-layer graphene by laser exfoliation. The graphene sheets are 

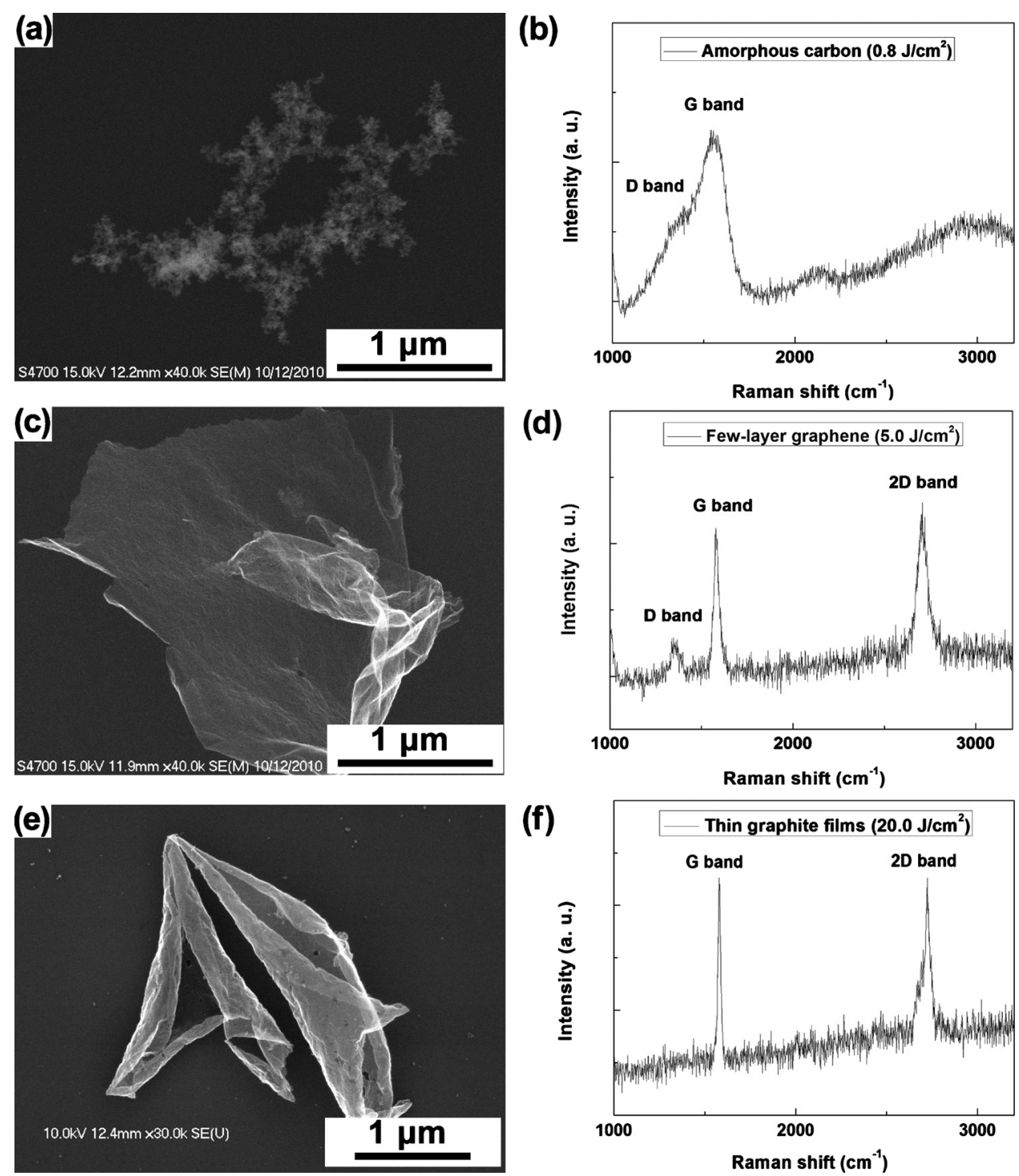

FIG. 4. (a) SEM image and (b) Raman spectrum of amorphous carbon obtained at $0.8 \mathrm{~J} / \mathrm{cm}^{2}$; (c) SEM image and (d) Raman spectrum of few-layer graphene obtained at $5.0 \mathrm{~J} / \mathrm{cm}^{2}$; and (e) SEM image and (f) Raman spectrum of thin graphite films obtained at $20.0 \mathrm{~J} / \mathrm{cm}^{2}$. formed on various substrates at room temperature, revealing their potential applications in electronics, optoelectronics, and mechanics.

This research work was financially supported by National Science Foundation (Grant No. CMMI 0758199), Nebraska Research Initiative, Nebraska Center for Energy Science Research, and Office of Naval Research (Grant Nos. MURI N00014-05-1-0432 and N00014-09-1-0943).

${ }^{1}$ K. S. Novoselov, A. K. Geim, S. V. Morozov, D. Jiang, Y. Zhang, S. V. Dubonos, I. V. Grigorieva, and A. A. Firsov, Science 306, 666 (2004).

${ }^{2}$ K. I. Bolotin, K. J. Sikes, J. Hone, H. L. Stormer, and P. Kim, Phys. Rev. Lett. 101, 096802 (2008).

${ }^{3}$ A. K. Geim and K. S. Novoselov, Nature Mater. 6, 183 (2007).

${ }^{4}$ Y. Q. Wu, P. D. Ye, M. A. Capano, Y. Xuan, Y. Sui, M. Qi, J. A. Cooper,

T. Shen, D. Pandey, G. Prakash, and R. Reifenberger, Appl. Phys. Lett. 92, 092102 (2008).

${ }^{5}$ X. S. Li, W. W. Cai, J. H. An, S. Kim, J. Nah, D. X. Yang, R. Piner, A. Velamakanni, I. Jung, E. Tutuc, S. K. Banerjee, L. Colombo, and R. S. Ruoff, Science 324, 1312 (2009).

${ }^{6}$ Y. X. Xu, H. Bai, G. W. Lu, C. Li, and G. Q. Shi, J. Am. Chem. Soc. 130, 5856 (2008).

${ }^{7}$ C. Soldano, A. Mahmood, and E. Dujardin, Carbon 48, 2127 (2010).

${ }^{8}$ J. Moser, A. Barreiro, and A. Bachtold, Appl. Phys. Lett. 91, 163513 (2007).

${ }^{9}$ Z. C. Ying, R. L. Hettich, R. N. Compton, and R. E. Haufler, J. Phys. B
29, 4935 (1996).

${ }^{10}$ G. Radhakrishnan, P. M. Adams, and L. S. Bernstein, Appl. Surf. Sci. 253, 7651 (2007).

${ }^{11}$ K. P. Acharya, H. Khatri, S. Marsillac, B. Ullrich, P. Anzenbacher, and M. Zamkov, Appl. Phys. Lett. 97, 201108 (2010).

${ }^{12}$ A. C. Ferrari, J. C. Meyer, V. Scardaci, C. Casiraghi, M. Lazzeri, F. Mauri, S. Piscanec, D. Jiang, K. S. Novoselov, S. Roth, and A. K. Geim, Phys. Rev. Lett. 97, 187401 (2006).

${ }^{13}$ J. S. Park, A. Reina, R. Saito, J. Kong, G. Dresselhaus, and M. S. Dresselhaus, Carbon 47, 1303 (2009).

${ }^{14}$ M. S. Dresselhaus, A. Jorio, M. Hofmann, G. Dresselhaus, and R. Saito, Nano Lett. 10, 751 (2010).

${ }^{15}$ D. B. Chrisey, A. Pique, R. A. McGill, J. S. Horwitz, B. R. Ringeisen, D. M. Bubb, and P. K. Wu, Chem. Rev. (Washington, D.C.) 103, 553 (2003). ${ }^{16}$ Z. Sun, S. M. Huang, Y. F. Lu, J. S. Chen, Y. J. Li, B. K. Tay, S. P. Lau, G. Y. Chen, and Y. Sun, Appl. Phys. Lett. 78, 2009 (2001).

${ }^{17}$ S. M. Huang, Y. F. Lu, and Z. Sun, Appl. Surf. Sci. 151, 244 (1999).

${ }^{18} \mathrm{~S}$. Houzumi, K. Takeshima, K. Mochiji, N. Toyoda, and I. Yamada, Electron. Commun. Jpn. 91, 40 (2008).

${ }^{19}$ J. C. Conde, F. Lusquinos, P. Gonzalez, J. Serra, B. Leon, L. Cultrera, D. Guido, and A. Perrone, Appl. Phys. A: Mater. Sci. Process. 79, 1105 (2004)

${ }^{20}$ A. A. Voevodin and M. S. Donley, Surf. Coat. Technol. 82, 199 (1996).

${ }^{21}$ H. O. Jeschke, M. E. Garcia, and K. H. Bennemann, Phys. Rev. Lett. 87, 015003 (2001).

${ }^{22}$ F. Carbone, P. Baum, P. Ruldolf, and A. H. Zewail, Phys. Rev. Lett. 100, 035501 (2008). 